\title{
Trowulan Sebagai Historic City: Mengkonstruksi Citra Melalui Pengelolaan Informasi
}

\section{Sugeng Riyanto}

Keywords: cultural resource management, conservation, utilization, majapahit, research, model

\section{How to Cite:}

Riyanto, S. (2004). Trowulan Sebagai Historic City: Mengkonstruksi Citra Melalui Pengelolaan Informasi. Berkala Arkeologi, 24(1), 87-100. https://doi.org/10.30883/jba.v24i1.897

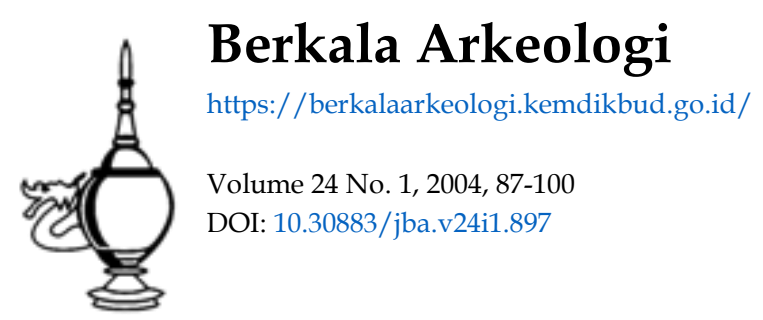

\section{(c) (1) (2) (2)}

This work is licensed under a Creative Commons Attribution-NonCommercial-ShareAlike 4.0 International License. 


\title{
TROWULAN SEBAGAI HISTORIC CITY: \\ Mengkonstruksi Citra Melalui Pengelolaan Informasi
}

\author{
Sugeng Riyanto
}

\section{RKEOLOGI DAN INFORMASI}

arkeologi, sebagaimana disiplin ilmu yang lain, meliputi proses dan tingkatan penelitian mulai dari pengumpulan data, pengolahan data, hingga penjelasan mengenai hasil penelitiannya. James Deetz menggambarkan tiga tingkatan dalam penelitian arkeologi mulai dari tahap observasi, deskripsi, dan eksplanasi (1967: 8). Melalui tiga tahapan ini akeolog akan ... be able to say many thing about past culture based on their scanty and imperfect remains (ibid.). Akan tetapi "say many thing about past culture" saja ternyata belum cukup dan bukan akhir dari kegiatan arkeologis. Tahap pasca penelitian, khususnya yang berkaitan dengan publikasi, sebenarnya sudah lama disadari akan arti pentingnya. Hal ini bukan sekedar sebagai tanggung jawab profesi, akan tetapi lebih penting dari itu adalah tanggung jawab moral untuk mengkomunikasikan hasil penelitian arkeologi kepada khalayak (Joukowsky, 1980: 457).

Bukan hanya itu, karena penelitian arkeologi (pada prinsipnya) dibiayai oleh masyarakat, maka secara profesional arkeolog memiliki tanggung jawab untuk menginformasikan hasil penelitiannya bukan saja kepada kalangan akademik tetapi juga kepada masyarakat luas (McGimsey \& Davis, 1977: 78). Mengkomunikasikan hasil penelitian arkeologi kepada masyarakat luas, dan bukan hanya kepada kalangan akademik, belakangan memang menjadi tuntutan yang tidak bisa ditawar lagi, seperti dijelaskan lebih lanjut oleh McGimsey \& Davis bahwa: ... while it will always be true that archaeologists need to communicate efectively among themselves, it now is abundantly clear that unless they also communicate effectively with the general public ... (ibid: 89 ).

Hasil penelitian arkeologi yang pada situs-situs tertentu dibarengi (atau ditindaklanjuti) dengan kegiatan konservasi, antara lain mewujudkan benda cagar budaya yang bersifat monumental maupun artefaktual dengan berbagai keunikannya. Tahap konservasi, selain ditujukan untuk pelestarian situs atau benda cagar budaya tertentu, juga diarahkan agar dapat dimanfaatkan. Berkaitan dengan pemanfaatan, Cleere (1989: 9-10) menjelaskan bahwa manajemen sumber daya arkeologi memiliki tiga tumpuan pemanfaatan, yaitu: ideologik yang terkait erat dengan pendidikan (edukasional) untuk mewujudkan "cultural identity"; ekonomik (keuntungan 
ekonomik melalui kepariwisataan); dan akademik (penelitian atau kegiatan ilmiah lainnya serta pengembangan ilmu).

Situs Trowulan di Kabupaten Mojokerto, Jawa Timur, adalah salah satu situs penting yang dimanfaatkan baik secara ideologik, akademik, maupun ekonomik sekaligus. Sejak Wardenaar, yang ditugaskan oleh Sir Thomas Raffles untuk mengamati peninggalan purbakala yang ada di Mojokerto, dan pada tahun 1815 berhasil membuat dokumen berupa gambar-gambar beserta keterangannya, dorongan untuk meneliti situs ini semakin besar, bahkan hingga saat ini. Salah satu hasil penelitian yang menonjol adalah bahwa kepurbakalaan tersebut dihubungkan secara sangat erat dengan Kerajaan Majapahit, sebuah kerjaan Hindu terakhir di Jawa yang berkembang dari tahun 1293 hingga 1478. Secara khusus, berbagai tinggalan yang tersebar menunjukkan bahwa Trowulan merupakan kota kuna. Bukan hanya itu, kegiatan arkeologis yang lain, yaitu konservasi, juga terus dilakukan, juga hingga saat ini.

\section{$\mathbf{B}$} INGKAI AKADEMIK SITUS TROWULAN

Sebelum ditemukan pertama kali oleh Wardenaar pada tahun 1815, "Kota" Trowulan memang dalam keadaan hancur. Berbagai kemungkinan tentang faktor kehancuran tersebut antara lain dikemukakan oleh Sartono dan Bandono (1991: 130) yang menyatakan ada dua faktor, yaitu politis dan alam. Faktor politis misalnya suksesi, perpindahan pusat pemerintahan (oleh Rajasanegara ke Tumapel pada tahun 1451), dan pendirian bangunan baru di atas bangunan lama sebagai usaha pemulihan kota. Sedangkan faktor alam adalah letusan Gunung Kelud yang terjadi berkali-kali yang bukan hanya menimbulkan goncangan hebat tetapi juga debu yang mengubur sebagian kota.

Pigeaud (1960-3, IV) menggambarkan beberapa aspek kehidupan Majapahit berdasarkan Nägararakrtägama, seperti penggolongan masyarakat yang terdiri atas empat kelompok, yaitu penguasa (rulers), pejabat keagamaan (men of religion), rakyat biasa (commoners), dan para abdi dalem (bondmen). Kehidupan ekonomi didasarkan pada pertanian yang dilakukan di tanah datar atau di punggung bukit dengan menggunakan sistem séngkédan, yang menghasilkan beras dan jelai. Jenis-jenis hewan yang dikonsumsi pada saat itu antara lain adalah katak, cacing, penyu, tikus, dan anjing. Sementara itu beberapa jenis minuman yang dikenal oleh masyarakat Majapahit meliputi tuak, dari pohon kelapa maupun lontar, arak dari pohon aren, kilang, brem, dan tampo (Pojoh, 1990: 221).

Secara khusus Parmono Atmadi (1993: 119-130) mengkaji aspek arsitektural terhadap tinggalan kepurbakalaan Majapahit baik yang bersifat monumen maupun lansekap (tata ruang). Kajian ini selain didasarkan pada pengamatan terhadap berbagai tinggalan yang ada juga didasarkan pada berbagai laporan terdahulu seperti: Maclaine 
Pont yang menyebut Javansche Architectur; W.F. Stutterheim yang membicarakan de Kedaton van Majapahit; T.G. Th. Pigeaud yang menguraikan dalam Bukunya Java in the $14^{\text {th }}$ Century. A Study in Cultural History; dan Prapanca dalam bukunya Nāgararakrtāgama.

Niken Wirasanti (1997) mengulas situs Trowulan sebagai kota pusat kerjaan Majapahit yang difokuskan pada masalah penggolongan kota menurut fungsinya (penggolongan non numerik) seperti kota sebagai pusat produksi, perdagangan, maupun pemerintahan. Diyakini bahwa Trowulan merupakan pusat kerajaan Majapahit sebagai sebuah kota yang tertata dengan kawasan-kawasan khusus, misalnya kawasan bangunan suci (candi), perumahan kelompok profesi dan industri, serta kelompok pedagang.

Kehidupan keagamaan masyarakat Majapahit antara lain tercermin dari ditemukannya sejumlah besar bangunan suci (candi) yang juga didukung oleh data tertulis. Selanjutnya Subroto (1997: 118) menjelaskan bahwa adanya tiga kepala keagamaan di Majaphit, yaitu Buddhadyaksa, Saiwadyaksa, dan Mantri er haji meupakan bukti adanya tiga agama, yaitu Buddha, Hindu, dan pertapa. Pengakuan terhadap tiga agama ini mencerminkan adanya usaha pemerintah pada waktu itu dalam memupuk rasa persatuan dan kesatuan melalui kehidupan bertoleransi dalam bidang keagamaan. Hal ini sangat jelas tergambar dari sisa-sisa Kota Trowulan kuna, khususnya tinggalan bangunan keagamaan.

Soekmono dan Inajati Adrisijanti (1993: 67-88) menguraikan tentang kejayaan dan dinamika Kerajaan Majapahit seperti tercermin dari berbaga tinggalan purbakala yang ada sebagai warisan. Warisan tersebut antara lain adalah:

- berbagai bangunan candi masa Majapahit yang tersebar di Jawa Timur

- peninggalan bercorak Islam khususnya nisan-nisan bertulis dari abad XIV M yang tersebar pada tujuh kelompok makam. Bentuk Nisan-nisan ini paling tidak meliputi 4 tipe yaitu: lengkung kala-makara, segi empat berujung akolade dan berpangkal antefiks, segi empat dengan tonojolan di atas, dan bentuk bertingkat.

Peneliti yang lain, Karina Arifin (1983), secara khusus membahas waduk dan kanal di Trowulan. Berdasarkan pandangan para ahli sebelumnya ditambah hasil penelitiannya (antara lain melalui analisis foto udara), dapat dipastikan bahwa kanal-kanal tersebut dibangun pada masa Majapahit. Selain itu, dikatakan bahwa fungsi utama waduk dan kanal adalah sebagai pengendali banjir, khususnya dalam rangka menyelamatkan kota dan lahan pertanian yang ada. Trowulan secara geografis memang berada pada bentang kipas alluvial sehingga sungai-sungai di sekitarnya cepat mengalami pendangkalan justru karena berada pada kipas alluvial. Percepatan pendangkalan ini berakibat langsung terhadap daya tampung sungai yang semakin rendah, sehingga ketika musim hujan potensi meluapnya air sungai sangat besar. 
Sampai dengan tahun 1993, berbagai kegiatan penelitian dan pendokumentasian di Trowulan dan sekitarnya telah dilakukan baik secara perorangan maupun secara institusional. Hasil berbagai kegiatan ini secara umum mengarah pada gambaran bahwa Trowulan merupakan bekas keraton sekaligus sebuah kota. Kegiatan tersebut adalah sebagai berikut (Rangkuti, tt: 7-9 dengan penyesuaian redaksional):

\begin{tabular}{|c|c|c|}
\hline TAHUN & NAMA / INSTITUSI & KEGIATAN \\
\hline 1815 & Wardenaar & $\begin{array}{l}\text { Pencatatan dan penggambaran beberapa } \\
\text { reruntuhan bangunan candi, fondasi } \\
\text { bangunan, sisa saluran air, arca-arca }\end{array}$ \\
\hline 1887 & $\begin{array}{l}\text { van Hoevll, Rigg, Veth, Knebel, } \\
\text { Aria Krama Djajadiningrat } \\
\text { (Bupati Mojokerto) }\end{array}$ & $\begin{array}{l}\text { Pengungkapan peninggalan-peninggalan } \\
\text { di Trowulan dan sekitarnya }\end{array}$ \\
\hline 1889 & Wardenaar & $\begin{array}{l}\text { Pembuatan denah dan gambar-gambar } \\
\text { yang berhubungan dengan upaya } \\
\text { rekonstruksi keraton Majapahit }\end{array}$ \\
\hline 1924 & Henry Maclaine Pont & $\begin{array}{l}\text { Rekonstruksi keraton dan kota Majapahit } \\
\text { berdasarkan Nāgararakrtāgama } \\
\text { sekaligus pengujian di lapangan } \\
\text { Pada tahun ini berdiri suatu badan swasta } \\
\text { Oudheidkundige Vereeniging Majapahit } \\
\text { untuk meneliti dan melestarikan } \\
\text { peninggalan purbakala di daerah ini }\end{array}$ \\
\hline 1926 & Henry Maclaine Pont & $\begin{array}{l}\text { Pencatatan tak kurang dari } 18 \text { waduk } \\
\text { besar masa Majapahitdi seluruh daerah di } \\
\text { Mojokerto, dan empat di antaranya } \\
\text { terdapat di Trowulan, yaitu: Baruneno, } \\
\text { Kumitir, Domas, dan Temon }\end{array}$ \\
\hline 1958 & $\begin{array}{l}\text { Lembaga Purbakala } \\
\text { Peninggalan Nasional }\end{array}$ & $\begin{array}{l}\text { Pemetaan situs yang mencakup bagian } \\
\text { selatan, Klinterejo di utara, } \\
\text { Bendorangkang di barat, dan Beloh di } \\
\text { timur }\end{array}$ \\
\hline 1966 & $\begin{array}{lrr}\text { Lembaga } & \text { Purbakala } & \text { dan } \\
\text { Peninggalan } & \text { Nasional } & \text { Kantor } \\
\text { Cabang III Jawa Timur } & \end{array}$ & $\begin{array}{l}\text { Penggalian di kolam Segaran untuk } \\
\text { mengetahui dasar kolam yang ternyata } \\
\text { mengandung endapan vulkanis }\end{array}$ \\
\hline 1974 & $\begin{array}{lcr}\text { Yayasan } & \text { Bina } & \text { Trowulan, } \\
\text { pengelola } & \text { bangunan } & \text { Pendopo } \\
\text { Agung } & & \end{array}$ & $\begin{array}{l}\text { Penggalian di situs Pendopo Agung } \\
\text { untuk mengetahui lebih lanjut kekunaan } \\
\text { di daerah ini }\end{array}$ \\
\hline 1976 & $\begin{array}{l}\text { Pusat Penelitian Purbakala dan } \\
\text { Peninggalan Nasional (kemudian }\end{array}$ & $\begin{array}{l}\text { Program penelitian jangka panjang } \\
\text { dalam upaya untuk merekonstruksi }\end{array}$ \\
\hline
\end{tabular}




\begin{tabular}{|c|c|c|}
\hline & $\begin{array}{l}\text { dikenal sebagai Pusat Penelitian } \\
\text { Arkeologi Nasional }- \text { Puslit } \\
\text { Arkenas) }\end{array}$ & $\begin{array}{l}\text { kehidupan perkotaan Majapahit dengan } \\
\text { segala aspeknya. Survei permukaan } \\
\text { secara sistematis (dengan sistem grid) } \\
\text { dilakukan di daerah Beloh, Bejijong, } \\
\text { Kejagan, Semen, Trowulan, Wonorejo, } \\
\text { Jatipasar, Temon, Sentonorejo, } \\
\text { Klinterejo, Panggih, Pakem Wetan, } \\
\text { Pakem Kulon, Watesumpak, Kalitangi, } \\
\text { Troloyo, dan Kumitir. Ekskavasi } \\
\text { dilakukan di situs Pendopo Agung, } \\
\text { sedangkan ekskavasi penyelamatan di } \\
\text { Pandan Sili. Penelitian ini merupakan } \\
\text { penelitian Tahap I }\end{array}$ \\
\hline \multirow[t]{2}{*}{1977} & 1. Puslit Arkenas & $\begin{array}{l}\text { 1. Melanjutkan ekskavasi di situs } \\
\text { Pendopo Agung (Tahap II) }\end{array}$ \\
\hline & 2. Kantor SPSP Jawa Timur & $\begin{array}{l}\text { 2. Ekskavasi di Segaran dengan } \\
\text { tujuan mengembalikan kepada fungsi } \\
\text { aslinya, yaitu kolam buatan }\end{array}$ \\
\hline 1978 & Puslit Arkenas & $\begin{array}{l}\text { Melanjutkan ekskavasi di situs Pendopo } \\
\text { Agung (Tahap III) }\end{array}$ \\
\hline 1979 & Puslit Arkenas & $\begin{array}{l}\text { Melanjutkan ekskavasi di situs Pendopo } \\
\text { Agung (Tahap IV) }\end{array}$ \\
\hline 1980 & $\begin{array}{l}\text { 1. Puslit Arkenas } \\
\text { 2. SPSP Jawa Timur }\end{array}$ & $\begin{array}{l}\text { 1. Melanjutkan ekskavasi di situs } \\
\text { Pendopo Agung (Tahap V) } \\
\text { 2.a Studi kelayakan arkeologi Balai } \\
\text { Penyelamatan Benda-benda Purbakala } \\
\text { di Dukuh Segaran } \\
\text { 2.b Penggalian sumur kuno di Dukuh } \\
\text { Nglinguk }\end{array}$ \\
\hline 1981 & $\begin{array}{l}\text { 1. Puslit Arkenas } \\
\text { 2. Bakosurtanal, Ditlinbinjarah, } \\
\text { UGM, ITB, dan LAPAN }\end{array}$ & $\begin{array}{l}\text { 1. Melanjutkan ekskavasi di situs } \\
\text { Pendopo Agung (Tahap V) serta di } \\
\text { situs Sentonorejo dan Sumur Upas } \\
\text { atau Kedaton } \\
\text { 2. inventarisasi dan pemetaan } \\
\text { peninggalan purbakala }\end{array}$ \\
\hline 1982 & $\begin{array}{l}\text { 1. Puslit Arkenas } \\
\text { 2. SPSP Jatim }\end{array}$ & $\begin{array}{l}\text { 1. Melanjutkan ekskavasi di situs } \\
\text { Pendopo Agung (Tahap VI) serta } \\
\text { Klinterejo } \\
\text { 2. penggalian di Sentonorejo }\end{array}$ \\
\hline
\end{tabular}




\begin{tabular}{|c|c|c|}
\hline \multirow[t]{2}{*}{1983} & 1. Puslit Arkenas & $\begin{array}{l}\text { 1. Melanjutkan ekskavasi di situs } \\
\text { Nglinguk (Tahap VII) }\end{array}$ \\
\hline & $\begin{array}{l}\text { 2. Ditlinbinjarah } \\
\text { 3. Tim Hidrologi UGM }\end{array}$ & $\begin{array}{l}\text { 2. Studi Kelayakan Arkeologi dalam } \\
\text { rangka pemugaran bekas Ibukota } \\
\text { Majapahit ( } 25 \text { Juli }-7 \text { Agustus) } \\
\text { 3. Pengeboran Geoelektrik untuk } \\
\text { mengetahui susunan material tanah } \\
\text { Trowulan }\end{array}$ \\
\hline 1984 & Puslit Arkenas & $\begin{array}{l}\text { Analisis genteng hasil ekskavasi di } \\
\text { Pendopo Agung }\end{array}$ \\
\hline 1985 & Puslit Arkenas & $\begin{array}{lrll}\text { Melanjutkan ekskavasi } & \text { di } & \text { situs } \\
\text { Sentonorejo dan Nglinguk } & & \end{array}$ \\
\hline 1986 & $\begin{array}{l}\text { 1. Puslit Arkenas } \\
\text { 2. UGM } \\
\text { 3. Ditlinbinjarah }\end{array}$ & $\begin{array}{l}\text { 1. Melanjutkan ekskavasi di situs } \\
\text { Nglinguk dan Kejagan (Kuburan } \\
\text { Cina) } \\
\text { 2. Ekskavasi di Segaran, di samping } \\
\text { gedung Balai Penyelamatan } \\
\text { 3. Penyusunan Rencana Induk Proyek } \\
\text { Pemugaran dan Pemeliharaan Bekas } \\
\text { Kota Kerajaan Majapahit }\end{array}$ \\
\hline 1987 & Puslit Arkenas & $\begin{array}{l}\text { Melanjutkan ekskavasi di situs Nglinguk } \\
\text { dan Batok Palung }\end{array}$ \\
\hline 1988 & Puslit Arkenas & $\begin{array}{l}\text { Melanjutkan ekskavasi di situs Batok } \\
\text { Palung dan Klinterejo }\end{array}$ \\
\hline 1989 & $\begin{array}{l}\text { 1. Puslit Arkenas } \\
\text { 2. UI }\end{array}$ & $\begin{array}{l}\text { 1. Melanjutkan ekskavasi di situs } \\
\text { Batok Palung dan Bledren } \\
\text { 2. Latihan Ekskavasi dan penelitian } \\
\text { arkeologi permukiman mikro di } \\
\text { Segaran (ahap I). Ekskavasi dilakukan } \\
\text { di halaman samping gedung Balai } \\
\text { Penyelamatan. }\end{array}$ \\
\hline 1990 & 1. Puslit Arkenas & $\begin{array}{l}\text { 1. Ekskavasi dan analisis geohidrologi } \\
\text { pada saluran di situs Bledren. } \\
\text { Serangkaian penelitian yang } \\
\text { dilakukan oleh Puslit Arkenas sejak } \\
\text { 1976 dihentikan pada tahun ini } \\
\text { 2. Melanjutkan ekskavasi di Segaran } \\
\text { (Tahap II) }\end{array}$ \\
\hline 1991 & Puslit Arkenas \& The Ford & Indonesian Field School of Archaeology, \\
\hline
\end{tabular}




\begin{tabular}{|c|c|c|}
\hline & Foundation & $\begin{array}{l}\text { survei permukaan secara sistematis dan } \\
\text { analisis tembikar - batuan - porselen }\end{array}$ \\
\hline 1992 & $\begin{array}{l}\text { 1. Puslit Arkenas \& The Ford } \\
\text { Foundation } \\
\text { 2. UI }\end{array}$ & $\begin{array}{l}\text { 1. Lanjutan Indonesian Field School } \\
\text { of Archaeology, survei permukaan } \\
\text { secara sistematis dan analisis } \\
\text { tembikar-batuan-porselen } \\
\text { 2. melanjutkan ekskavasi di Segaran } \\
\text { (Tahap III/ Januari dan Tahap IV/ } \\
\text { September) }\end{array}$ \\
\hline 1993 & $\begin{array}{l}\text { 1. UI } \\
\text { 2. Puslit Arkenas \& The Ford } \\
\text { Foundation }\end{array}$ & $\begin{array}{l}\text { 1. Melanjutkan ekskavasi di Segaran } \\
\text { (Tahap V) } \\
\text { 2. Lanjutan Indonesian Field School } \\
\text { of Archaeology, survei permukaan } \\
\text { secara sistematis dan analisis } \\
\text { tembikar - batuan - porselen }\end{array}$ \\
\hline
\end{tabular}

\section{$\mathbf{K}$} ERANGKA PERSOALAN

Bingkai akademik sebagai dasar untuk menggambarkan kota Trowulan kuna secara ilmiah telah menunjukkan bahwa Trowulan merupakan situs yang sangat penting, baik dalam kerangka sejarah Indonesia kuna maupun sebagai warisan yang dapat dikembangkan dan dimanfaatkan. Namun demikian, kondisi situs ini oleh berbagai kalangan dianggap sedang mengalami kerusakan yang terus berlanjut, di samping berbagai persoalan yang ada, baik persoalan citra, persoalan pelestarian, maupun persoalan pemanfaatannya. Tiga persoalan inilah yang hingga sekarang masih membelenggu situs Trowulan.

Betapa kompleks dan rumitnya persoalan tersebut, apalagi jika masing-masing aspek diuraikan satu demi satu. Persoalan citra, misalnya, terdapat perbedaan yang mencolok antara kalangan akademik (institusi penelitian, pelestarian, dan perguruan tinggi), kalangan pemerintah (Bappeda dan Dinas Pariwisata baik provinsi maupun kabupaten), dan masyarakat (khususnya penduduk setempat). Bagi kalangan akademik, citra situs Trowulan adalah sebagai bekas keraton Majapahit, atau sekurang-kurangna bekas daerah kekuasaan Majapahit (Pojoh, 1990: 222). Oleh karena itu, secara ilmiah situs ini harus diselamatkan karena arti pentingnya, baik untuk pengembangan ilmu maupun pengembangan pemanfaatannya. Bagi kalangan pemerintah, citra situs Trowulan adalah sebagai aset yang harus dikembangkan dengan orientasi ekonomik sejati, sehingga pengembangannya berada pada bingkai pemasukan secara finansial (PAD). Bagi masyarakat, situs Trowulan merupakan bidang tanah yang potensial, baik untuk industri bata, lokasi perburuan harta karun, 
maupun pemasukan finansial dari berbondong-bondongnya para peziarah di makam kuna yang sebenarnya merupakan bagian dari kota.

Hal inilah yang melatarbelakangi pentingnya mengembalikan citra situs Trowulan yang sebenarnya. Citra ini semestinya dibangun dari hasil-hasil kegiatan akademik baik penelitian maupun pelestarian - dan harus dikomunikasikan secara efektif kepada masyarakat luas. Dengan demikian hal ini akan mengarah pada interpretasi yang harus disampaikan kepada berbagai pihak. Citra situs Trowulan sebagai salah satu cermin dan simbol kejayaan Kerajaan Majapahit, yang dibangun secara ilmiah khususnya oleh para arkeolog, tidak boleh berhenti dan hanya beredar di kalangan akademik.

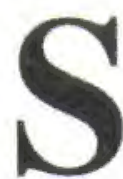

\section{IGNIFIKANSI}

Menurut Peter Howard, interpretasi yang dikomuniasikan meliputi interpretasi langsung dan kemasan. Interpretasi langsung dilakukan melalui pemanduan sedangkan

kemasan interpretasi interpretation") bentuknya antara lain meliputi: pameran, leaflet, label, audio-video, IT system (multi media), tata suara, musik, replika, contoh/peniruan (2003: 260). McGimsey dan Hester A. Davis mengemukakan bahwa penyampaian informasi kepada masyarakat meliputi bentuk

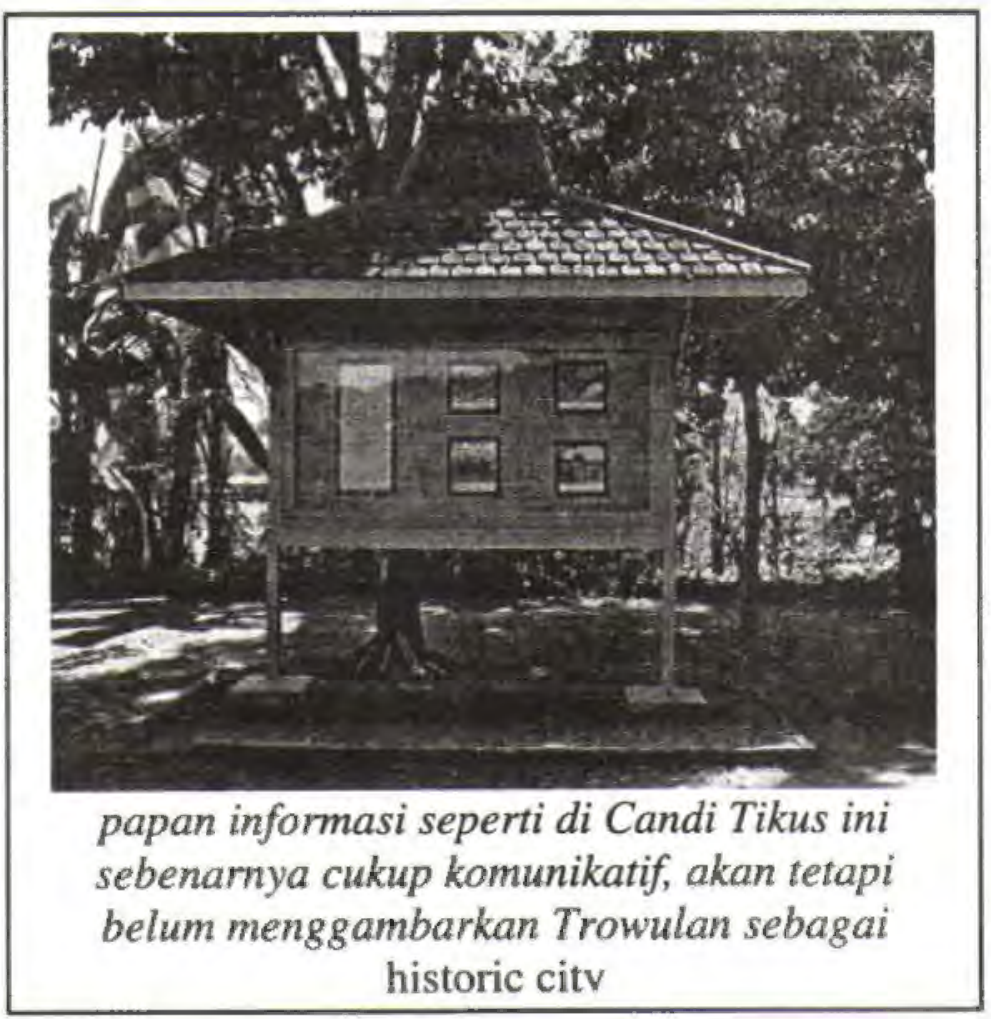

kemasan tulis (written word), lisan (spoken word), dan visual (visual presentation) seperti tayangan TV; video, dan museum (1977: 85-87).

Haryati Soebadio (1993/1994: 4-9) secara khusus menyoroti pemanfaatan peninggalan sejarah yang dibaginya menjadi dua, yaitu pemanfaatan fisik (pariwisata) dan pemanfaatan non-fisik (berkaitan dengan makna kultural) yang keduanya dapat berjalan bersama. Khusus untuk pemanfaatan non-fisik, penyebarluasan pengetahuan hasil penelitian kepada masyarakat luas dianggap sangat penting, dan untuk lingkungan awam agar diusahakan penjelasan yang mudah dicerna (ibid.). Obyek yang ada di Situs Trowulan adalah produk budaya masa lalu dan merupakan simbol 
yang mengandung makna kultural sebagai salah satu cermin kejayaan Kerajaan Majapahit. Peran arkeolog dalam hal ini adalah mempresentasikan benda simbolis ini agar signifikan dan bermakna baik bagi generasi penciptanya maupun generasi selanjutnya melalui interpretasi yang disajikan kepada masyarakat (Poespowardojo, 1993/1994: 17-18). Interpretasi ini sekaligus dijadikan sebagai salah satu intsrumen untuk meningkatkan apresiasi masyarakat.

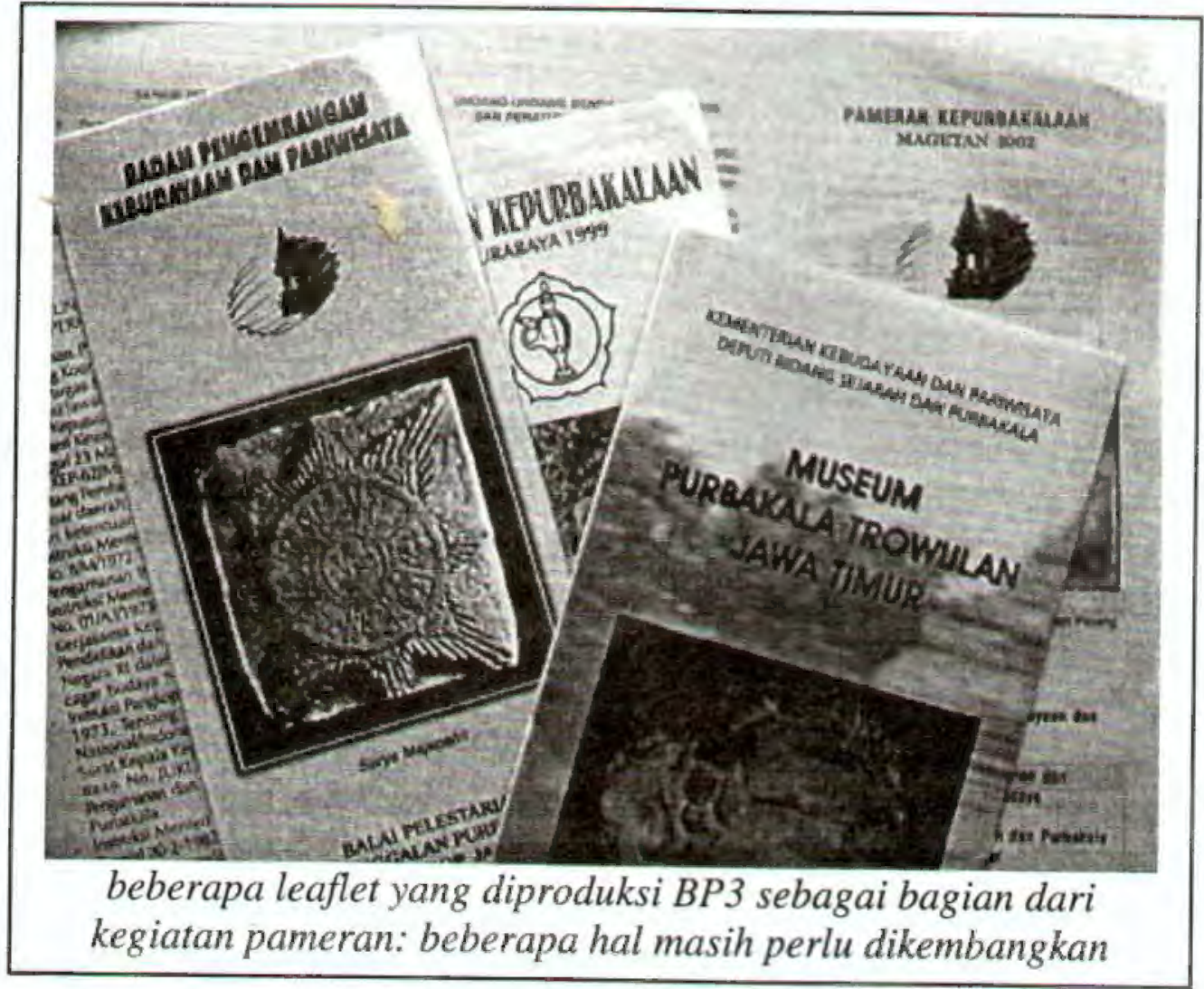

Peningkatan apresiasi terhadap citra situs Trowulan pada khususnya dan warisan budaya pada umumnya diharapkan akan mendorong masyarakat untuk lebih kritis terhadap kelestarian dan pemanfaatannya. Selain itu, apresiasi masyarakat terhadap benda cagar budaya dapat mendukung program pelestarian karena pelestarian dapat dimulai dari peningkatan apresiasi terhadap benda cagar budaya (Haryono, 2003b: 10). Kelestarian sumber daya arkeologi pada gilirannya dan dalam batas tertentu dapat dimanfaatkan yang oleh Cleere (1989: 10) dibedakan dalam tiga tumpuan pemanfaatan, yaitu ideologik (edukasional), akademik (ilmu pengetahuan), dan ekonomik (pariwisata). Secara mendasar antara pelestarian dan pemanfaatan memang terlihat adanya hubungan yang resiprokal sekaligus potensial.

Hubungan resiprokal antara pelestarian dan pemanfaatan, khususnya pariwisata, sekaligus merupakan dua kepentingan yang strategis (Haryono, 2003a: 9). Semenara itu, beberapa kerangka pemikiran untuk mendekati persoalan yang resiprokal ini antara lain adalah konsep peddle or perish (Macleod, 1977: 63-72) yang pada intinya menyatakan bahwa benda cagar budaya dilestarikan untuk "dijual" (dimanfaatkan) dan benda cagar budaya dimanfaatkan demi kelestarian; atau dengan kalimat lain "jual atau musnah".

Dengan pengelolaan informasi yang mudah dipahami dan mudah diakses, maka studi untuk pengembangan berbagai disiplin ilmu melalui situs Trowulan merupakan 
manfaat akademik yang paling utama. Secara ideologik, sebagai bahan untuk pendidikan baik formal maupun non-formal dengan tujuan utama untuk meningkatkan apresiasi masyarakat, maka pengemasan informasi yang ideal memang tidak bisa ditawar lagi. Sementara itu, pemanfaatan secara ekonomik dikembangkan dalam kerangka kepariwisataan. Ketersediaan informasi yang dikelola sedemikian rupa akan menciptakan citra Trowulan sebagai historic city. Dengan citra sebagai histoic city, maka prinsip pariwisata yang meliputi something to see, something to do, dan something to buy akan mudah dicapai, tentu saja berbekal dan berorientasi pada bingkai akademik (baik penelitian maupun pelestarian).

\section{Denutur}

Beberapa butir penting mengenai pengelolaan informasi di situs Trowulan, khususnya sebagai historic city, adalah sebagai berikut:

- Berdasarkan bingkai akademik, dapat dipastikan bahwa Trowulan merupakan kota kuna (historic city) dengan kehidupan masyarakatnya yang sangat dinamis.

- Citra trowulan ternyata tidak hanya ditempatkan sebagai historic city tetapi oleh beberapa kalangan dipandang dan ditempatkan dengan citra yang berbeda. Pemda (dalam hal ini Bappeda dan Dinas Pariwisata) memandang Trowulan sebagai aset yang harus dikembangkan untuk meningkatkan PAD melaui pariwisata dengan orientasi ekonomik sejati. Sementara itu masyarakat setempat menempatkan Trowulan sebagai: 1) bidang tanah yang potensial untuk produksi bata, 2) lokasi perburuan harta karun, dan 3) sumber pemasukan informal melalui kegiatan peziarahan. Perbedaan citra ini merupakan salah satu dasar persoalan yang membelenggu Trowulan hingga saat ini. Secara langsung, hal ini juga berpengaruh pada persoalan kelestarian dan pemanfaatan. Dengan demikian, untuk membangun citra historic city seperti dihasilkan oleh berbagai peneliti, pengelolaan informasi menjadi sangat penting artinya.

- Sebagai salah satu unsur paling penting, pengelolaan informasi di Trowulan hingga saat ini banyak memiliki keterbatasan, sehingga perlu dikembangkan. Pengembangan pengelolaan ini paling tidak meliputi written word, spoken word, dan visual presentation.

- Pengelolaan informasi yang ideal, antara lain bermanfaat secara akademik (sebagai bahan pengembangan ilmu), ideologik (peningkatan apresiasi masyarakat), dan ekonomik (bagian dari atraksi dan pelayanan kepariwisataan). Seperti dikatakan oleh Yoeti (2002: 3) bahwa produk industri pariwisata harus memenuhui kebutuhan (needs), keinginan (wants), dan harapan (expection) para wisatwan. Berkaitan dengan hal ini, sebagai bagian dari produk industri pariwisata, layanan informasi yang dikembangkan diharapkan dapat menjadi bagian dari sesuatu yang dibutuhkan, diinginkan, dan diharapkan. 
Berdasarkan butir-butir di atas, kerangka pemikiran yang bisa dioperasionalkan antara meliputi:

- Pembentukan jaringan pengelolaan: pengembangan pengelolaan informasi seperti diuraikan di atas jelas tidak bisa dilaksanakan oleh satu organisasi tertentu. Banyak pihak yang terkait sehingga secara langsung harus terlibat, baik dalam hal perencanaan maupun pelaksanaannya. Bukan hanya itu, sesuai dengan prinsip pemasyarakatan, maka jaringan ini juga mencakup proses produksi sekaligus distribusi. Dalam jaringan ini juga perlu untuk melibatkan kalangan masyarakat luas (pengusaha Biro Perjalanan dan Wisata, Hotel, pengusaha lainnya yang terkait), serta masyarakat setempat (jajarang kecamatan, kelurahan, tokoh masyaakat, LSM).

- Samsat: untuk lebih efektif dalam pelaksanaan jaringan pengelolaan tersebut, sebenarnya sangat dimungkinkan untuk membentuk semacam "sistem adminsitrasi satu atap (samsat)" yang terdiri atas: kalangan akademik (instansi penelitian, perguruan tinggi, dan instansi pelestarian) dan Pemda (Bappeda, Dinas Pariwisata, dan organisasi terkait lainnya)

- Membuat perencanaan program bersama dalam mengelola sumber daya arkeologi di Trowulan dalam kerangka historic city. Perencanaan ini antara lain dapat mengacu pada konsep heritage management yang dikembangkan oleh Pearson \& Sharon Sullivan (1995: 191) mulai dari pendokumentasian dan inventarisasi terpadu, penilaian (signifikasi dan manajerial), perumusan kebijakan program, penentuan strategi manajerial, serta penyusunan konsep operasional yang meliputi beberapa strategi (pemeliharaan, konservasi, manajemen kunjungan wisata, serta strategi lainnya yang dianggap perlu). Dalam pelaksanaannya, unsur monitoring dan evaluasi sangat penting, antara lain sebagai dasar untuk penilaian ulang serta proses selanjutnya. 


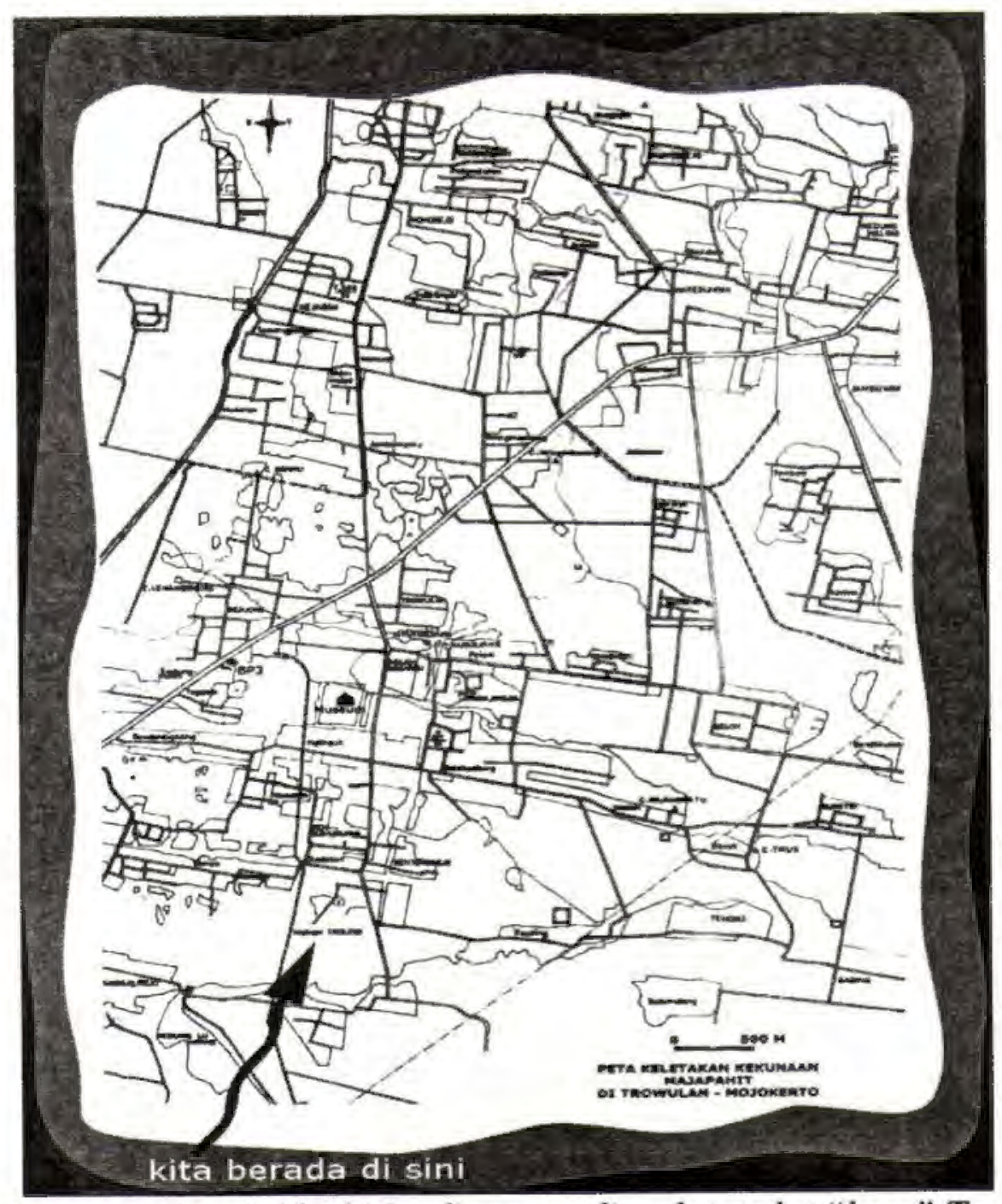

Contoh peta navigasi: ideal jika dipasang di sudut-sudut "kota" Trowulan, sehingga "saya tahu sedang berada di bagian kota yang mana 


\section{KEPUSTAKAAN}

Arifin, Karina. 1983. Waduk dan Kanal di Pusat Kerajaan Majapahit, Trowulan Jawa Timur. Skripsi. Jakarta: FS UI.

Atmadi, Parmono. 1993. "Bunga Rampai dan Pola Kota Kraton Majapahit". Dalam Sartono Katodirdjo, dkk. (eds.), 700 Tahun Majapahit (1293-1993) Suatu Bunga Rampai. Surabaya: Dinas Pariwisata Daerah Propinsi Dati I Jawa Timur. HIm. 119-130.

Cleere, Henry. 1989. "Introduction: The Rationale of Archaeological Heritage Management". Henry F. Cleere (ed.) Archaeological Heritage Management in the Modern World. London: Unwin Hyman. pp. 1-19.

Deetz, James. 1967. Invitation to Archaeology. New York: The National History Press.

Haryono, Timbul. 2003. Pelestarian Warisan Budaya Dunia. Makalah disampaikan dalam Seminar Pelestarian Candi Prambanan sebagai Warisan Budaya Dunia di Prambanan, Yogyakarta, 10-11 September 2003.

Hodder, Ian. 1999. The Archaeological Process An Introduction. Oxford: Blackwell Publisher Ltd.

Howard, Peter. 2003. Heritage, Management, Interpretation, Identity. London: Continuum.

Joukowsky, Martha. 1980. A Complete Manual of Field Archaeology. Tools and Techniques of Field Work for Archaeologists. New Jersey: Prenfice-Hale, Inc.

Macleod, Donald G. 1977. "Peddle or Perish: Archaeological Marketing from Concept to Product Delivery". Michael B. Schiffer \& George J. Gumerman (eds.). Conservation Archaeology A Guide for Cultural Resources Management Studies. New York: Academic Press. Hlm. 63-72.

McGimsey, Charles R. \& Hester A. Davis (eds). 1977. The Management of Archaeological Resources, The Airlie House Report. Special publication of the Society for American Archaeology. Washington D.C. 
Pearson, Michael \& Sharon Sullivan. 1995. Looking After Heritage Places. Melbourne: Melbourne University Press.

Pigeaud, T.G.Th. 1960. Java in the $14^{\text {th }}$ Century. A Study in Cultural History. 5 vols. 's-Gravenhage: Matinus Nijhoff.

Poespowardojo, Soerjanto. 1993/1994. "Arkeologi dan Jatidiri Bangsa". Dalam Proceedings Pertemuan Ilmiah Arkeologi VI. Jakarta: Pusat Penelitian Arkeologi Nasional. HIm. 15-21.

Pojoh, Ingrid H.E. 1990. "Terakota dari Situs Trowulan, Kabupaen Mojokerto, Jawa Timur”. Dalam Monumen, Karya Persembahan untuk Prof. Dr. R. Soekmono. Depok: F.S. UI. HIm. 219-245.

Rangkuti, Nurhadi, tt. Langkah Penelitian Situs Trowulan. Makalah lepas.

Sartono, S \& Bandono. 1991. "Kehancuran Majapahit dari Pandangan Geologi". Dalam Proceeding Analisis Hasil Penelitian Arkeologi (AHPA) II. Jakarta: Depdikbud. Hlm. 125-131.

Soebadio, Haryati. 1993/1994. "Arkeologi dan Pengembangan Sosial-Budaya Bangsa". Dalam Proceedings Pertemuan Ilmiah Arkeologi VI. Jakarta: Pusat Penelitian Arkeologi Nasional. HIm. 3-13.

Soekmono, R. \& Inajati Adrisijanti. 1993. "Peninggalan-peninggalan Purbakala Masa Majapahit”. Dalam Sartono Katodirdjo, dkk. (eds.), 700 Tahun Majapahit (1293-1993) Suatu Bunga Rampai. Surabaya: Dinas Pariwisata Daerah Propinsi Dati I Jawa Timur. HIm. 67-88.

Subroto, Ph. 1997. "Kondisi Situs Trowulan dan Usaha-usaha Pelestariannya". Dalam Proceeding Saresehan Pelestarian dan Pemanfaatan Situs Trowulan. Mojokerto: Suaka Peninggalan Sejarah dan Purbakala Jawa Timur. HIm. 111 130.

Wirasanti, Niken. 1997. "Situs Trowulan: Perkotaan Masa Klasik". Dalam Proceeding Saresehan Pelestarian dan Pemanfaatan Situs Trowulan. Mojokerto: Suaka Peninggalan Sejarah dan Purbakala Jawa Timur.HIm. 7189.

Yoeti, H. Oka A. 2002. Perencanaan Strategis Pemasaran Daerah Wisata. Jakarta: PT Pradnya Paramita. 